\title{
Urethral sleeve sensor: a non-withdrawal method to measure maximum urethral pressure
}

\author{
Jasmine Tan-Kim • Milena M. Weinstein • \\ Charles W. Nager
}

Received: 9 August 2009 /Accepted: 14 December 2009/Published online: 14 January 2010

(C) The Author(s) 2010. This article is published with open access at Springerlink.com

\begin{abstract}
Introduction and hypothesis This study seeks to evaluate axial variation, comparisons with current technology, performance during dynamic conditions, and patient tolerability of the urethral sleeve sensor (USS) for maximal urethral closure pressure (MUCP) measurements.

Methods Eighteen continent and seven stress incontinent women underwent assessments with USS and urethral pressure profilometry (UPP) in random order. Intravesical $\left(p_{\text {ves }}\right)$ and urethral $\left(p_{\text {ura }}\right)$ pressure signals were collected and urethral closure pressure $\left(p_{\text {clo }}\right)$ was calculated. A visual analog scale (VAS) was used to evaluate subject discomfort. Results The correlation coefficient between MUCP obtained by UPP and USS techniques was $0.86(p<0.001)$. Higher USS pressures were obtained with catheter oriented to 12 o'clock. Continent subjects demonstrated higher values of $p_{\text {clo }}$. MUCP became $<0 \mathrm{~cm} \mathrm{H}_{2} \mathrm{O}$ in subjects with clinical leakage during Valsalva, but not in continent subjects. Subjects tolerated the USS technique better than the UPP technique on VAS $(p<0.001)$.
\end{abstract}

\section{J. Tan-Kim $\cdot$ C. W. Nager}

Department of Reproductive Medicine, Division of Female Pelvic

Medicine and Reconstructive Surgery, University of California,

San Diego,

La Jolla, CA, USA

\section{M. Weinstein}

Division of Urogynecology and Reconstructive Pelvic Surgery, Massachusetts General Hospital, Vincent Gynecology,

Boston, MA, USA

C. W. Nager $(\bowtie)$

UCSD Women's Pelvic Medicine Center,

9350 Campus Point Dr., Suite 2A,

La Jolla, CA 92037, USA

e-mail: cnager@ucsd.edu
Conclusions USS technology can be used to evaluate the urethra in both static and dynamic conditions and is better tolerated than withdrawal techniques.

Keywords Profilometry · Sleeve sensor · Urethral pressure · Urodynamics

\section{Introduction}

Whenever bladder pressure exceeds urethral pressure, urinary incontinence or bladder emptying occurs. Activities that increase intra-abdominal pressure (such as coughing, straining, or exercising) result in a corresponding increase in bladder pressure and if that bladder pressure exceeds urethral pressure, stress urinary incontinence (SUI) results. Urethral pressure is typically measured as a profile using a small microtip transducer, a perfused side-hole, or a small air balloon on a semi-rigid catheter which is withdrawn through the length of the urethra with a puller device at a determined rate. These techniques collect pressure measurements at discrete sites along the urethra and a graph indicating the pressure at each of these sites along the length of the urethra is known as the urethral pressure profile (UPP) [1]. Only a small portion of the urethra can be measured at any given instant and these techniques often take $30 \mathrm{~s}$ or more to obtain and therefore do not allow reliable measurements of the maximum urethral pressure during Valsalva maneuvers or pelvic floor muscle contractions which cannot be maintained for that time period without fatigue. Some investigators place the catheter in a stationary position when maximum urethral pressure is reached and attempt to measure maximum urethral pressure during dynamic conditions such as Valsalva, cough, or during a pelvic floor muscle contraction (PFMC). However, 
these dynamic activities often produce a slight migration of the catheter sensor away from the peak of the bell-shaped maximum urethral pressure zone and if the pressure decreases, it cannot be determined if this decrease is real or artifact.

Perfused sleeve sensor technology, commonly called the Dent sleeve, is a well-accepted technique that has been used for more than 30 years measuring maximal pressures in gastrointestinal sphincters such as the esophagus or anal canal [2-4]. The sleeve sensor consists of a long thinwalled silicone sleeve that is glued along the catheter. The sleeve is positioned such that it remains in contact with the sphincter and is constantly perfused with fluid. Sphincter squeeze acts on the sleeve to cause increased resistance to the flow of water through it. This increased resistance is directly related to the greatest squeeze acting on the sleeve and causes back pressure to perfusion. This principle is similar to constantly perfused side-hole catheters. The unique quality of this perfused sleeve is its ability to record maximum pressure measurements anywhere along the length of the sleeve without requiring withdrawal of the catheter. If the maximum pressure zone of a sphincter resides within the sleeve, the sleeve will record the maximum pressure of the sphincter. A reverse-perfused sleeve sensor has demonstrated a faster response rate than a conventional sleeve [3]. We could not find literature to suggest that Dent sleeve technology has been used in the urethra.

Our study objectives are to evaluate the urethral sleeve sensor (USS) for urethral pressure measurements. The aims of this study are fourfold: (1) to determine if there are axial variations with sleeve sensor technology in the urethra, (2) to compare maximum urethral closure pressures (MUCP) using sleeve sensor technology with maximum urethral closure pressures obtained by water perfusion UPP, (3) to determine if sleeve sensor technology measures respond appropriately during dynamic conditions such as Valsalva or PFMC in normal and stress incontinent women, and (4) to determine patient discomfort with this technology compared to water perfusion UPP.

\section{Materials and methods}

The study population consists of 18 continent women volunteers and seven women with stress dominant urinary incontinence scheduled for diagnostic urodynamic studies. The study was approved by the institutional review board and written informed consent was obtained. The subjects were at least 18 years of age, without evidence of a UTI, prolapse, previous incontinence surgery, and they completed the UDI-6 [5] and IIQ-7 [5] for a characterization of their urinary continence or incontinence status. Continent subjects reported "never" on questions 2, 3, and 4 of the UDI-6 which specifically inquire about stress urinary incontinence symptoms. The stress incontinent patients had demonstrable stress incontinence during office evaluation.

\section{Subject evaluation}

After voiding, all subjects had a Foley catheter inserted into the bladder and a post-void residual was obtained. The bladder was filled to $200 \mathrm{ml}$. Gentle traction was placed on the catheter to bring the balloon to the urethral-vesical junction and the urethral length was measured by marking the catheter at the level of the external meatus. The catheter was then removed and a stress test was performed with Valsalva and coughing, first in the supine position and then standing if leakage was not observed supine.

All subjects then underwent assessments with the USS and conventional water perfusion UPP. The order of the two procedures was randomized to eliminate bias attributable to tolerance or fatigue. Stress incontinent patients also underwent conventional filling cystometry and pressureflow studies as part of their clinical evaluation.

\section{Urethral sleeve sensor}

Figure 1 illustrates the sleeve catheter measuring system and the catheter positioning in the urethra and bladder. The reverse-perfused sleeve sensor catheter is $2.5 \mathrm{~mm}$ in diameter $(7.8 \mathrm{Fr})$ and made of soft, flexible silicone and was specially manufactured for our purposes (MUI Scientific Inc., Mississauga, ON, Canada, www.dentsleeve.com). At the distal end of the catheter, a perfused side-hole measures intravesical pressure. Two centimeters proximal from the distal end, the sleeve sensor begins on the catheter and extends $5 \mathrm{~cm}$ in length proximally. Based on the urethral length measurements, the sleeve sensor is positioned in the urethra so that the sleeve's distal end is $1 \mathrm{~cm}$ from the urethral-vesical junction and the remainder of the sleeve clearly resides within the entire rest of the urethra including the mid-urethral high pressure zone. The sleeve sensor is connected to the external transducers. Prior to catheter insertion, both the intravesical and intraurethral measuring systems were zeroed to atmospheric pressure with the catheter and transducers at the level of the patient's urethra. Room temperature sterile water in a pressurized bag at $300 \mathrm{~cm} \mathrm{H}_{2} \mathrm{O}$ was perfused through the system at $0.5 \mathrm{ml} / \mathrm{min}$. This perfusion rate was chosen because: (a) it is used for reverse-perfused sleeve sensors [3]; (b) a lower perfusion rate is associated with a lower pressure error [6]; and (c) it can be reliably achieved with a commercially available flow restrictor (Uniflow Flush Device $30 \mathrm{ml} / \mathrm{h}$, Edwards Lifesciences, Irvine, CA, USA). 
Fig. 1 Schematic drawing of the urethral sleeve sensor (USS). At the distal end of the catheter, a perfused side-hole measures intravesical pressure (\#1 sidehole) Fluid is perfused through the lumen of the catheter (\#2-Sleeve) from left to right in the drawing and then reverseperfused through the sleeve from right to left. $p_{\text {ura }}$ urethral pressure transducer, $p_{\text {ves }}$ vesical pressure transducer

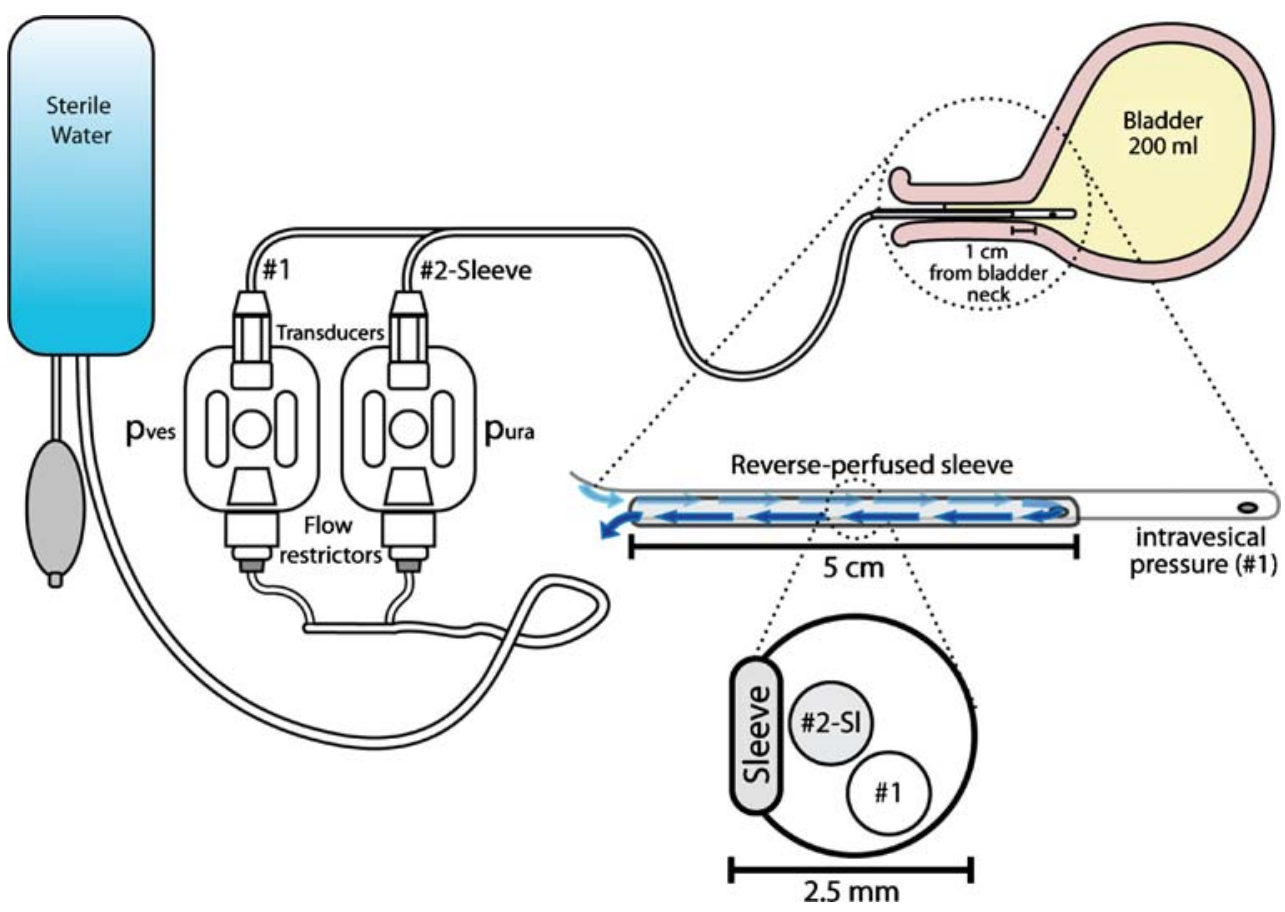

Pressure measurements were taken during three coughs, three Valsalva maneuvers, and three pelvic floor muscle contractions with the sleeve oriented at 3, 6, 9, and 12 o'clock. The sequence of axial variation measurements was randomized. The catheter was secured in place during the various maneuvers, and the urethral meatus was observed to determine leakage. For PFMC, subjects were asked to "contract their pelvic muscles as if trying to prevent urination or passing gas," and each subject was coached until they could do this maneuver properly. Intravesical pressure $\left(p_{\text {ves }}\right)$ and urethral pressure $\left(p_{\text {ura }}\right)$ tracings were collected continuously throughout the study and a third signal recorded urethral closure pressure $\left(p_{\text {clo }}\right)$ by continuously subtracting $p_{\text {ves }}$ from $p_{\text {ura }}$. The pressure readings were all recorded on Laborie urodynamic software (Laborie Medical Technologies, Williston, Vermont, USA).

\section{Urethral pressure profilometry}

Water-perfused UPPs were chosen for comparison to the sleeve catheter because the ICS has defined urethral pressure as the fluid pressure needed to just open a closed urethra [1]. For UPP measures, the same perfusion system that was used for the sleeve sensor measures was used with a 7 French Laborie triple lumen water perfusion catheter. Measurements were obtained with the catheter laterally oriented to the 9 o'clock position and withdrawn at $1 \mathrm{~mm} / \mathrm{s}$ with a mechanical puller. Three separate measurements of $p_{\text {ves }}, p_{\text {ura }}$, and $p_{\text {clo }}$ were obtained from three separate pulls with the patient at rest.
At the completion of their entire evaluation study, subjects were asked to complete a $0-100 \mathrm{~mm}$ VAS scoring their discomfort for the UPP and the USS urodynamic techniques.

\section{Statistical analyses}

Means and standard deviations for normally distributed data and medians for non-normal distributed data are calculated and presented. SPSS v.11 (SPSS Inc., Chicago, IL, USA) was utilized for statistical analysis. Laterality data regarding the four different orientations of the USS and the associations between maximum pressures obtained by the sleeve sensor or UPP urethral pressure profile were evaluated with Pearson's correlation coefficients. The limits of the two different measurement techniques, the USS and UPP, were calculated as described by Bland and Altman [7]. $P$ values of $<0.05$ was considered statistically significant. A priori power calculations determined that a total of 18 subjects were needed to achieve a correlation coefficient of 0.8 with $80 \%$ power and $\alpha=0.5$ for comparison of USS and UPP.

\section{Results}

The 18 continent subjects had a mean age of 40 years (range 23-57), median parity of 1 (range $0-8$ ), mean weight of $157 \mathrm{lbs}$ (range 100-325), mean body mass index of $27 \mathrm{~kg} / \mathrm{m}^{2}$ (range 17-48), mean urethral length of $4.3 \mathrm{~cm}$ (SD 0.48), and all had post-void residuals less than $40 \mathrm{ml}$. 
The seven stress incontinent subjects had a mean age of 65 years (range 47-83), median parity of 3 (range 0 5), mean weight of $169 \mathrm{lbs}$ (range 129-205), mean body mass index of $29 \mathrm{~kg} / \mathrm{m}^{2}$ (range 24-35), mean urethral length of $4.3 \mathrm{~cm}$ (SD 0.63 ), and all had post-void residuals less than $80 \mathrm{ml}$. These incontinent subjects had a mean UDI-6 score of 60 (range 25-79) and IIQ-7 score of 44 (range 14-81).

\section{Urethral sleeve sensor signals}

Because of response time limitations with a water-perfused system, the urethral sleeve sensor technology does not accurately measure rapid pressure changes from events such as a cough, although cough signals are observed in both the bladder and urethra measuring systems. Figure $2 \mathrm{a}$ is an example of a typical signal obtained from a continent subject. During Valsalva maneuvers, there is minimal to no change from baseline for $p_{\text {clo }} ; p_{\text {clo }}$ remains positive and no leakage occurs. A properly performed PFMC produces an increase in $p_{\text {ura }}$ with no increase in $p_{\text {ves }}$ and therefore an increase in $p_{\text {clo }}$ above resting baseline (Fig. 2a, b).

Figure $2 \mathrm{~b}$ is an example of a typical signal from an incontinent subject. Valsalva maneuvers produce a bladder pressure that exceeds urethral pressure, $p_{\text {clo }}$ becomes negative, and leakage is observed. During PFMC, the maximum total $p_{\text {clo }}$ pressure is less than in the continent individual.

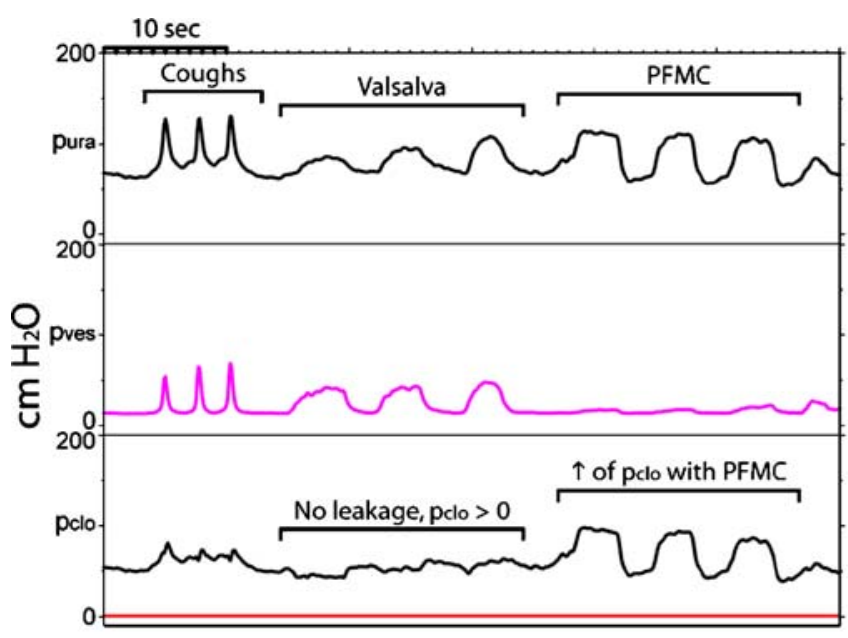

a. Continent Subject

Fig. 2 a Typical signals from a continent subject. $p_{\text {ura }}$ and $p_{\text {ves }}$ are measured using the urethral sleeve sensor. $p_{\text {clo }}$ is the subtracted value of $p_{\text {ves }}$ from $p_{\text {ura }}$. All pressures are expressed in centimeters of water on the $y$-axis. Time is on the $x$-axis. During Valsalva, the continent subject increases her abdominal pressure and vesical pressure $\left(p_{\text {ves }}\right)$, and there is a corresponding increase in urethral pressure $\left(p_{\text {ura }}\right)$. The subject is able to maintain $p_{\text {clo }}>0$, and no leakage is observed. During PFMC, the continent patient is able to increase her $p_{\text {clo }}$ pressures by increasing her $p_{\text {ura }}$. This subject is clearly performing the PFMC

\section{Axial variation}

The 12 o'clock position produced different (higher) results than the 3, 6, and 9 o'clock results. Measurements were compared in a pair wise fashion. The mean differences between the other three positions was $<7 \mathrm{~cm} \mathrm{H}_{2} \mathrm{O}$ with correlation coefficients $>0.84$, but the difference between the three other orientations and the 12 o'clock orientation were between 10 and $17 \mathrm{~cm} \mathrm{H}_{2} \mathrm{O}$ with correlation coefficients of $<0.83$. This 12 o'clock deviation in the correlation relative to the other orientations is sufficiently different enough to warrant exclusion of the 12 o'clock data from all further calculations. This exclusion of 12 o'clock data is also consistent with urodynamic literature on urethral axial variation [8-11].

Comparison of water perfusion MUCP and sleeve sensor MUCP

Figure 3 is a scatterplot demonstrating the mean water perfusion MUCP on the $y$-axis and the mean urethral sleeve sensor MUCP on the $x$-axis for all 25 subjects. The correlation coefficient between these two methods of maximum urethral closure pressure measurement is 0.86 $(p<0.001)$. However, pressure measurements obtained with catheter withdrawal (UPP) were typically higher than pressure measurements without withdrawal (USS), and the mean difference between the UPP and USS was $26.3 \mathrm{~cm}$

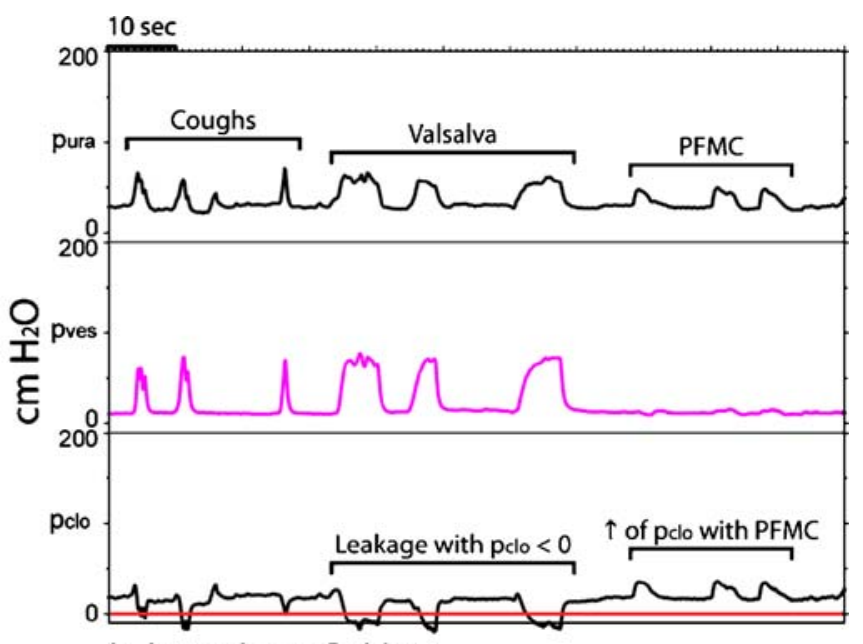

correctly because there is no increase in $p_{\text {ves. }} p_{\text {ura }}$ urethral pressure, $p_{\text {ves }}$ vesical pressure, $p_{c l o}$ urethral closure pressure, $P F M C$ pelvic floor muscle contraction. b Typical signals from an incontinent subject. During Valsalva, the incontinent subject is unable to maintain her urethral closure pressures when vesical pressure increases and $p_{c l o}$ becomes $<0 \mathrm{~cm} \mathrm{H}_{2} \mathrm{O}$, resulting in urine leakage. Even in the incontinent subject there is a modest increase in $p_{\text {clo }}$ during a properly performed PFMC 


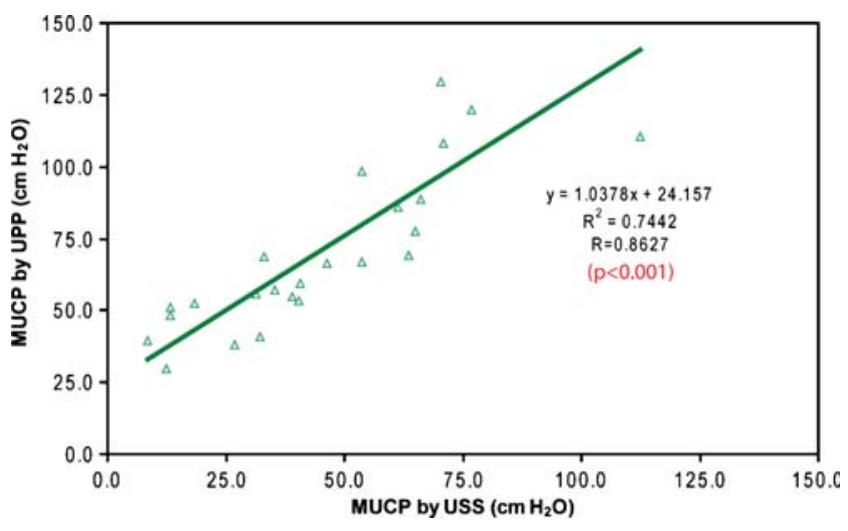

Fig. 3 Correlation between MUCP with UPP technique and USS technique. There is a high correlation of 0.86 between the two techniques $(p<0.001)$. Based on this equation, $74 \%$ of the variability can be explained by this model $(n=25)$. MUCP maximum urethral closure pressure, UPP urethral pressure profilometry, USS urethral sleeve sensor

$\mathrm{H}_{2} \mathrm{O}$ for all subjects. The $95 \%$ confidence interval for the limits of agreement are $-6.16 \mathrm{~cm} \mathrm{H}_{2} \mathrm{O}$ and $58.76 \mathrm{~cm} \mathrm{H}_{2} \mathrm{O}$ based on the technique described by Bland and Altman [7].

Pelvic floor muscle contraction

Table 1 shows the mean $p_{\text {clo }}$ pressures at baseline and with PFMC in continent and incontinent subject groups. Two continent subjects and one incontinent subject were unable to perform the PFMC despite verbal coaching and were excluded from this analysis. Continent subjects demonstrated significantly greater values of baseline $p_{\text {clo }}, p_{\text {clo }}$ with PFMC, and change in pressure than incontinent subjects.

All 18 continent volunteers had a negative cough and Valsalva stress test at $200 \mathrm{ml}$, and all seven incontinent subjects had a positive stress test with Valsalva. Table 2 demonstrates sleeve urodynamic findings in the two groups. The urethral closure pressure declined to $0 \mathrm{~cm} \mathrm{H}_{2} \mathrm{O}$ during a Valsalva maneuver in all of the incontinent subjects, but in none of the continent volunteers.

Subject tolerance of urodynamic techniques

Twenty-three of 25 subjects completed the VAS for discomfort. The discomfort score $(\operatorname{mean} \pm \mathrm{SD})$ for the USS
$(22 \pm 18 \mathrm{~mm})$ was significantly less than for the UPP technique (51 $\pm 27 \mathrm{~mm} ; p<0.001$; Fig. 4).

\section{Discussion}

Our study aims were to evaluate a GI manometric technique for possible use in the urethral sphincter. We found that MUCPs measured by a sleeve sensor have reasonable correlation $(r=0.86, p<0.01)$ with MUCPs measured with a conventional profilometry technique, although measurements are higher with profilometry. The correlation suggests that both methods measure the same biological phenomena: urethral pressure. The sleeve sensor has the potential to record maximal urethral pressure measures under dynamic conditions like Valsalva and pelvic floor muscle contraction when catheter migration with conventional systems can produce false decreases in maximum pressure recordings. We have also shown that the USS has good sensitivity and specificity for detecting incontinence based on $\mathrm{MUCP}<0$ during Valsalva maneuver. We also found that similar to other studies of urethral pressure, the urethral sleeve sensor is most consistent when the catheter is oriented to the 3,6 , or 9 o'clock position. Finally, this technique is well tolerated; the sleeve sensor does not require withdrawals and subjects report that the conventionally performed UPP using a puller was at least twice as uncomfortable as the sleeve sensor.

The sleeve sensor was specifically designed for the evaluation of dynamic sphincters within a biological system. Dent originally introduced the sleeve catheter device for obtaining a continuous recording of lower esophageal sphincter pressures [4]. It was devised for measuring the serial change of maximal lower esophageal sphincter pressure without the need for catheter manipulation. The sleeve is a collapsible membrane that measures the maximal sphincter pressure at any point along the sleeve and the sensor is suitable for monitoring continuous pressures of biological sphincters [2, 4]. The sleeve has been validated in human models in the gastroenterology literature [2, 3]. Linehan et al. have demonstrated that the sleeve device functions as a Starling resistor to record sphincter pressure [2]. As long as any part of the sleeve remains within the urethral high pressure zone, then minor

Table $1 p_{\text {clo }}$ pressures at baseline and with PFMC in continent and incontinent subject groups

\begin{tabular}{|c|c|c|c|}
\hline & Continent $n=16$ mean (SD) & Incontinent $n=6$ mean (SD) & $p$ value \\
\hline$p_{\text {clo }}$ baseline $\left(\mathrm{cm} \mathrm{H}_{2} \mathrm{O}\right)$ & $59(22)$ & $19(8)$ & $<0.001$ \\
\hline$p_{\text {clo }}$ with PFMC $\left(\mathrm{cm} \mathrm{H}_{2} \mathrm{O}\right)$ & $83(27)$ & $28(10)$ & $<0.001$ \\
\hline$\Delta$ pressure with PFMC $\left(\mathrm{cm} \mathrm{H}_{2} \mathrm{O}\right)$ & $23(15)$ & $8(4)$ & 0.02 \\
\hline Percent increase in pressure with PFMC (\%) & $43(28)$ & $46(32)$ & 0.83 \\
\hline
\end{tabular}


Table 2 Sleeve urodynamic findings in subjects who leaked or did not leak during separate standardized clinical Valsalva stress testing

\begin{tabular}{lll}
\hline Sleeve urodynamic findings & $\begin{array}{l}\text { Clinically continent } \\
\text { (no leakage with Valsalva) }\end{array}$ & $\begin{array}{l}\text { Clinically incontinent } \\
\text { (leakage with Valsalva) }\end{array}$ \\
\hline Valsalva MUCP $>0$ & 18 & 0 \\
Valsalva MUCP $>0$ & 0 & 7 \\
\hline
\end{tabular}

movements of the catheter do not affect measurement results and maximal pressure is measured. As a result, the sleeve catheter is not prone to slippage artifact commonly encountered with methods which measure a discrete point along the urethra, it does not require a puller, and it is able to measure a pressure over a prolonged amount of time.

Similar to other reports in the literature, we found that the accuracy of the urethral pressure readings deviated most when the sleeve catheter was placed in the 12 o'clock position. Several other studies evaluating axial variations of the UPP in continent and incontinent females also found that MUCP was always higher in the anterior direction (12 o'clock) [8-11]. We concur with the stated literature and recommend that the urethral sleeve sensor be oriented in the lateral position for all evaluations.

Although an excellent correlation between the waterperfused UPP and the USS is demonstrated, pressures averaged $26 \mathrm{~cm} \mathrm{H}_{2} \mathrm{O}$ higher with the UPP. Water-perfused systems do seem to produce higher urethral pressures than microtip catheter systems. In a study by Wang and Chen, the average pressure obtained from the double-lumen water perfusion catheter was $24.5 \mathrm{~cm} \mathrm{H}_{2} \mathrm{O}$ higher than that from the microtip catheter in all age groups [12]. Another possible reason for higher pressures during the UPP withdrawal technique compared to the sleeve sensor is because the urethra probably does not relax during withdrawal techniques; the withdrawal technique could produce an involuntary reflex or voluntary contraction of the urethra. This phenomenon is well known in anal manometry

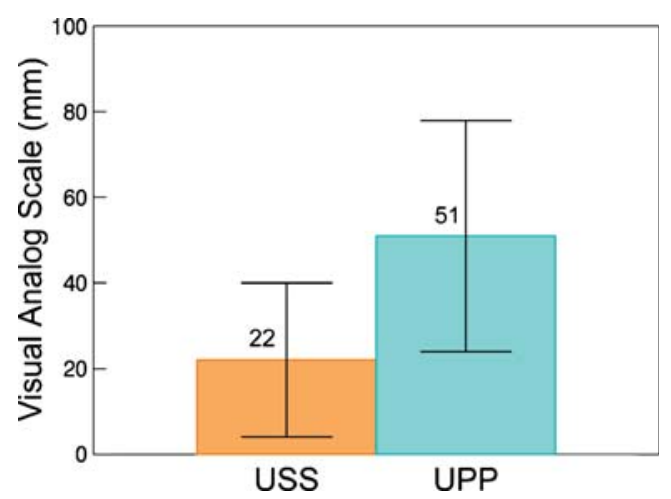

Fig. 4 Bar graph demonstrates the visual analog scale for discomfort with urethral pressures obtained by the USS and the UPP techniques $(n=23)(p<0.001)$ literature; when a catheter is continuously withdrawn through the anal canal the moving catheter produces a reflex or voluntary contraction of the anal sphincter and the resting anal canal pressures are inaccurately high. For this reason, most GI manometrists use sleeve sensor or interrupted "station" measures taken at finite intervals for true anal resting pressures. We think the sleeve technology is a technology to measure maximum urethral pressure along the length of the urethra in a true resting condition.

Other technologies can also potentially measure maximum urethral pressure without withdrawal techniques. Klarskov and Lose describe placing a polyurethane bag in the urethra and measuring pressure by acoustic reflectometry [13]. A catheter with multiple microtransducers along its length could theoretically also measure maximum pressure without withdrawal.

The sleeve sensor has potential for pelvic floor muscle training because it can provide direct urethral pressure measures during biofeedback. Conventional biofeedback equipment utilizes probes with surface EMG sensors or balloons in the vagina and relies on measuring vaginal pressure as a surrogate for urethral closure pressure [14]. Valsalva maneuvers can give false results [15]. With the sleeve sensor, if a patient improperly performs a Valsalva maneuver instead of a PFMC, the $p_{\text {ves }}$ pressures increases and a patient can be instructed that she is not contracting the correct muscles.

Limitations of the sleeve catheter (as with all waterperfused systems) are its inability to accurately measure fraction of second events such as a cough or sneeze. The sleeve sensor may not discriminate between continent and incontinent subjects if the patient only leaks with cough and not with Valsalva. A technical limitation is that the sleeve needs to be properly positioned so that the sleeve is always in the maximum urethral pressure zone, but not in the bladder, where it would measure bladder pressures rather than urethral pressure if bladder pressure were higher. Since maximum pressure is usually at mid-urethra and the typical urethra is $4 \mathrm{~cm}$ in length, by positioning the upper end of the sleeve $1 \mathrm{~cm}$ from the urethral-vesical junction, we are capturing the high pressure zone with our measures. Current studies are underway with a catheter that has an inflatable balloon $0.5 \mathrm{~cm}$ above the distal end of the sleeve to insure proper positioning of the sleeve with a single catheter insertion. We are currently evaluating a different 
sleeve sensor catheter which also contains a lumen for bladder filling and we are using the sleeve catheter during filling cystometry and pressure-flow studies. Preliminary observations confirm urethral relaxation during voiding and flow when $p_{\text {clo }}=0$.

\section{Conclusions}

The urethral sleeve sensor measuring system is a technique used in GI manometry that is well suited for measuring maximum sphincter pressures. This study demonstrates that it can be used in the urethral sphincter to measure maximum urethral pressure without the limitations of catheter withdrawal systems. It correlates well with the current UPP methods and functions as expected in continent and incontinent subjects. The sleeve sensor has potential to allow direct biofeedback measures of the urethra during pelvic floor muscle contractions. Further studies are underway to evaluate its use during filling and emptying studies.

Acknowledgment The authors acknowledge Ravi K. Mittal, MD, Professor of Medicine, Division of Gastroenterology, UCSD School of Medicine, for introducing sleeve sensor technology to the senior author.

\section{Conflicts of interest None.}

Open Access This article is distributed under the terms of the Creative Commons Attribution Noncommercial License which permits any noncommercial use, distribution, and reproduction in any medium, provided the original author(s) and source are credited.

\section{References}

1. Abrams P et al (2003) The standardisation of terminology in lower urinary tract function: report from the standardisation sub- committee of the international continence society. Urology 61 (1):37-49

2. Linehan JH et al (1985) Sleeve device functions as a starling resistor to record sphincter pressure. Am J Physiol 248(2 Pt 1): G251-G255

3. Sivri B, Mittal RK (1991) Reverse-perfused sleeve: an improved device for measurement of sphincteric function of the crural diaphragm. Gastroenterology 101(4):962-969

4. Dent J (1976) A new technique for continuous sphincter pressure measurement. Gastroenterology 71(2):263-267

5. Shumaker SA et al (1994) Health-related quality of life measures for women with urinary incontinence: the incontinence impact questionnaire and the urogenital distress inventory. Continence Program in Women (CPW) Research Group. Qual Life Res 3(5):291-306

6. Brown M, Wickham JE (1969) The urethral pressure profile. Br J Urol 41(2):211-217

7. Bland JM, Altman DG (1986) Statistical methods for assessing agreement between two methods of clinical measurement. Lancet 1(8476):307-310

8. Van Geelen JM, Doesburg WH, Martin CB Jr (1984) Female urethral pressure profile; reproducibility, axial variation and effects of low dose oral contraceptives. J Urol 131(2):394-398

9. Dompeyre P et al (1999) [Comparative study of 230 women to determine the maximum closure pressure and functional length of the urethra at 0, 3, 6 and 9 o'clock]. Prog Urol Prog Urol 9 (6):1090-1095 discussion 1095-1096

10. Masuda H et al (1997) Study of directional differences on static and stress urethral pressure profiles of female urethra. Nippon Hinyokika Gakkai Zasshi 88(1):40-45

11. Anderson RS, Shepherd AM, Feneley RC (1983) Microtransducer urethral profile methodology: variations caused by transducer orientation. J Urol 130(4):727-728

12. Wang AC, Chen MC (2002) A comparison of urethral pressure profilometry using microtip and double-lumen perfusion catheters in women with genuine stress incontinence. Bjog 109 (3):322-326

13. Klarskov N, Lose G (2007) Urethral pressure reflectometry vs urethral pressure profilometry in women: a comparative study of reproducibility and accuracy. BJU Int 100(2):351-356

14. Theofrastous JP et al (2002) Effects of pelvic floor muscle training on strength and predictors of response in the treatment of urinary incontinence. Neurourol Urodyn 21(5):486-490

15. Bo K et al (1990) Pelvic floor muscle exercise for the treatment of female stress urinary incontinence: II. Validity of vaginal pressure measurements of pelvic floor muscle strength and the necessity of supplementary methods for control of correct contraction. Neurourol Urodyn 9(5):479-487 